\title{
Causes of plasma flow bursts and dayside auroral transients: An evaluation of two models Invoking reconnection pulses and changes in the $Y$ component of the magnetosheath field
}

Article

Published Version

Lockwood, M., Cowley, S. W. H., Sandholt, P. E. and Løvhaug, U. P. (1995) Causes of plasma flow bursts and dayside auroral transients: An evaluation of two models Invoking reconnection pulses and changes in the $Y$ component of the magnetosheath field. Journal of Geophysical Research, 100 (A5). pp. 76137626. ISSN 0148-0227 doi: https://doi.org/10.1029/94JA02264 Available at https://centaur.reading.ac.uk/38807/

It is advisable to refer to the publisher's version if you intend to cite from the work. See Guidance on citing.

Published version at: http://dx.doi.org/10.1029/94JA02264

To link to this article DOI: http://dx.doi.org/10.1029/94JA02264

Publisher: American Geophysical Union

All outputs in CentAUR are protected by Intellectual Property Rights law, including copyright law. Copyright and IPR is retained by the creators or other copyright holders. Terms and conditions for use of this material are defined in the End User Agreement. 


\section{www.reading.ac.uk/centaur}

\section{CentAUR}

Central Archive at the University of Reading

Reading's research outputs online 


\title{
Causes of plasma flow bursts and dayside auroral transients: An evaluation of two models invoking reconnection pulses and changes in the $Y$ component of the magnetosheath field
}

\author{
M. Lockwood, ${ }^{1}$ S. W. H. Cowley, ${ }^{2}$ P. E. Sandholt, ${ }^{3}$ and U. P. Løvhaug ${ }^{4}$
}

\begin{abstract}
Longitudinal flow bursts observed by the European Incoherent Scatter (EISCAT) radar, in association with dayside auroral transients observed from Svalbard, have been interpreted as resulting from pulses of enhanced reconnection at the dayside magnetopause. However, an alternative model has recently been proposed for a steady rate of magnetopause reconnection, in which the bursts of longitudinal flow are due to increases in the field line curvature force, associated with the $B_{y}$ component of the magnetosheath field. We here evaluate these two models, using observations on January 20, 1990, by EISCAT and a 630- nm all-sky camera at Ny Ålesund. For both models, we predict the behavior of both the dayside flows and the 630-nm emissions on newly opened field lines. It is shown that the signatures of steady reconnection and magnetosheath $B_{y}$ changes could possibly resemble the observed $630-\mathrm{nm}$ auroral events, but only for certain locations of the observing site, relative to the ionospheric projection of the reconnection $\mathrm{X}$ line: however, in such cases, the flow bursts would be seen between the 630-nm transients and not within them. On the other hand, the model of reconnection rate pulses predicts that the flows will be enhanced within each $630-\mathrm{nm}$ transient auroral event. The observations on January 20, 1990, are shown to be consistent with the model of enhanced reconnection rate pulses over a background level and inconsistent with the effects of periodic enhancements of the magnitude of the magnetosheath $B_{y}$ component. We estimate that the reconnection rate within the pulses would have to be at least an order of magnitude larger than the background level between the pulses.
\end{abstract}

\section{Introduction}

The first report of a longitudinal band of red $(630 \mathrm{~nm})$ emission in the dayside auroral ionosphere was made by Sandford [1964]. From the ratios of emission intensities of the spectral lines, Eather and Mende [1971] showed that this emission was caused by "soft" electron precipitation. In the same year, Frank [1971] and Heikkila and Winningham [1971] reported observations of just such precipitation, with the discovery of solar wind plasma within magnetosphere in the region termed "cusp" or "cleft": the association with the red aurora being made by Heikkila [1972]. Whalen et al. [1971] showed that the red-dominant aurora was poleward of the dayside auroral oval (as later viewed from space in the

\footnotetext{
${ }^{1}$ Rutherford Appleton Laboratory, Chilton, Didcot, United Kingdom.

${ }^{2}$ Blackett Laboratory, Imperial College, London, United Kingdom.

${ }^{3}$ Department of Physics, University of Oslo, Blindern, Oslo, Norway

${ }^{4}$ EISCAT Scientific Association, Ramfjordmoen, Ramfjordbotn, Norway.
}

Copyright 1995 by the American Geophysical Union.

Paper number 94JA02264.

0148-0227/95/94JA-02264\$05.00
UV emission lines [Elphinstone et al., 1992]). The cusp/cleft precipitation is known to cause considerable heating of the thermal ionospheric electron gas [Titheridge, 1976; Brace et al., 1982] and this thermally excites much of the red aurora [Mantas and Walker, 1976; Rees and Roble, 1986; Wickwar et al., 1974; Wickwar and Kofman, 1984; Lockwood et al., 1993a].

The dayside aurora, as observed by white-light cameras (which are most sensitive to 557.7-nm green-line emissions) was shown to migrate equatorward following southward turnings of the interplanetary manetic field (IMF), and hence during the growth phases of substorms as open flux is eroded from the dayside and accumulated in the tail lobe [Vorobjev et al., 1975; Horwitz and Akasofu, 1977]. The 630-dominant aurora was also shown to move rapidly equatorward following southward turnings [Sandholt et al., 1983], such that it reaches lowest latitudes at the end of substorm growth phases, consistent with the motion of the cusp/cleft precipitation region [Burch, 1973; Meng 1983]. Hence magnetopause reconnection causes the latitude of the dayside red aurora to be highly anticorrelated with the substorm $A_{E}$ index, as is observed to be the case [Eather, 1985].

Starkov and Feldstein [1967] noted that the dayside aurora (as seen in white light) displays structured forms. Vorobjev et al. [1975] and Horwitz and Akasofu [1977] also noted that these discrete forms generally drift poleward at speeds of typically $0.5-1 \mathrm{~km} \mathrm{~s}^{-1}$. They break away from the band of dayside aurora while it drifts equatorward, indicating a relationship with the reconnection causing the equatorward 
migration of the band. These poleward moving events have been extensively studied in both 557.7- and 630-nm emissions using instruments on the Svalbard islands, one of the few locations in the northern hemisphere where the cusp/cleft aurora can be observed, and then only at new moon near winter solstice [Sandholt, 1988; Sandholt et al., 1985, 1989a, b]. The observations show that southward IMF is almost both a necessary and a sufficient condition for the occurrence of these events [Sandholt, 1988; G.J. Fasel, Dayside poleward-moving auroral forms: a statistical study, submitted to J. Geophys. Res., 1994 (hereinafter referred to as Fasel, submitted manuscript, 1994)] which therefore are observed when the cusp/cleft is at lower latitudes [Lockwood et al., 1989b]. In addition, they show longitudinal motion which depends on the sense of IMF $B_{y}$ : for positive $B_{y}$ the events move westward (for northern hemisphere observations) [Sandholt et al., 1990; Sandholt, 1988], whereas for $B_{y}$ $<0$ they move eastward [Sandholt et al., 1992, 1993]. Transient events with dominant 630-nm emissions are relatively broad (several hundred kilometers), and have thin (typically $10 \mathrm{~km}$ ) $557.7-\mathrm{nm}$-dominant arcs and arc fragments on one edge [Lockwood et al., 1993c].

Observations of the variation of plasma flow in and around such dayside auroral transients have been made using the EISCAT radar by Lockwood et al. [1989a, b, 1990, 1993c], Sandholt et al. [1990], and Moen et al. [1995]. The results show that the passage of a region of $630-\mathrm{nm}$-dominant emission corresponds to a large burst of east/west flow (when IMF $\left|B_{y}\right|$ is large), such that the plasma flow velocity equals the phase velocity of the optical event motion. The only known explanation of the $B_{y}$-dependent east/west plasma flow within these events is that they are made up of newly opened field lines and therefore are subject to the field line curvature force which generates the Svalgaard-Mansurov effect in E region currents [Atkinson, 1972; Jørgensen et al., 1972; Cowley, 1981] . Furthermore, the longitudinal motion of these events is greatest early in their lifetime and slows as their poleward drift increases, consistent with the pattern of motion of newly opened field lines as they evolve toward the tail lobe under the declining influence of the curvature force (i.e., as the field lines straighten) and the increasing magnetosheath flow [Lockwood et al., 1989a, b]. The transient 557.7nm emission has been shown to be the region of upward field-aligned current needed to transfer the longitudinal flow inside the $630-\mathrm{nm}$ transient from the magnctopause to the ionosphere [Lockwood et al., 1989b, 1993c; Sandholt et al., 1990]. Flows and 630-nm transients consistent with small $\left|B_{y}\right|$ have been presented by Lockwood et al. [1993b].

Questions then arise as to why the flows are pulsed and why the optical transients form, propagate, and fade. In the above series of papers, Sandholt et al. [1989a, b, 1990, 1992, 1993] and Lockwood et al. [1989a, b, 1990, 1993a, b, c] invoked pulsed reconnection, each pulse generating a region of newly opened flux on which magnetosheath-like electron precipitation generates a $630-\mathrm{nm}$ auroral patch. These then move, initially under the magnetic curvature force and subsequently under magnetosheath flow, as the newly open field lines evolve into the tail lobe: they then fade because in the lobe, the magnetosheath particles crossing the magnetopause flow away from the Earth (the high-altitude plasma "mantle") and very few precipitate into the ionosphere (see following section). This model predicts that such events should be seen in association with magnetopause flux transfer events (FTEs). To date, there has been only one opportunity to make simultaneous observations of the cusp/cleft aurora and flows and FTEs at the magnetopause. In this one case, a correspondence between magnetopause FTEs (or when very close to the current layer, the expected $B_{L}$ spikes) and dayside auroral transient/flow burst events was indeed observed [Elphic et al., 1990]. An indication that this association may be more general has been provided by Fasel (submitted manuscript, 1994), who has shown that the distribution of the repeat periods of poleward moving dayside auroral events is very similar to that for magnetopause FTEs, as reported by Lockwood and Wild [1993].

Newell and Sibeck [1993] have recently proposed an alternative explanation of these events, namely that the flow bursts are simply caused by steady reconnection with quasiperiodic enhancements of the magnetosheath $\left|B_{y}\right|$ (possibly caused by enhanced compression of the magnetosheath by solar wind dynamic pressure), via the Svalgaard-Mansurov effect. (Sec also debate by Lockwood et al. [1994] and Newell and Sibeck [1994]).

In the following two parts of this introduction, we consider the effects of magnetosheath $B_{y}$ changes and of pulses of enhanced reconnection rate on both the plasma flow and the $630-\mathrm{nm}$ aurora produced by magnetosheathlike plasma precipitation. In subsequent sections, we describc two examples of dayside auroral transients, seen by optical instruments at Ny Ålesund, Svalbard, and by the EISCAT UHF radar at Troms $\varnothing$. In the last section we evaluate the two models as possible explanations of these events.

\section{Ionospheric Effects of Changes in Magnetosheath $B_{y}$}

Figure 1 illustrates how changes in the $B_{y}$ component of the magnetic field in the magnetosheath would effect the convection and the $630-\mathrm{nm}$ aurora in the dayside highlatitude ionosphere of the northern hemisphere. The poleward direction is to the top of each schematic and dawn is to the left. To isolate the effect of the magnetosheath field change, steady state is assumed in all other respects. In particular, following Newell and Sibeck [1993], the reconnection rate at the dayside magnetopause is taken to be constant and the merging gap to be static. Figure 1 can be seen to refer to steady state because flow streamlines only cross the open/closed boundary at the ionospheric projection of the reconnection $X$ line (the "merging gap," shown as a dashed line), as the boundary is static (see discussion by Lockwood and Cowley [1992]).

To match the observations discussed later in this paper, the magnetosheath $B_{y}$ component is taken at all times to be negative, giving eastward flow on newly opened field lines in the northern hemisphere. This longitudinal ionospheric flow asymmetry corresponds to the Svalgaard-Mansurov effect in Hall currents, due to the curvature force on the newly opened field lines (the so-called "tension" force) [Jørgenson et al., 1972; Atkinson, 1972; Cowley, 1981]. All arguments we present here would also apply (with appropriate sense of longitudinal flow) to the opposite polarity of magnetosheath $B_{y}$ and to the southern hemisphere [Greenwald et al., 1990].

Magnetosheath plasma continuously gains access to the magnetosphere along open field lines [Dungey, 1968; Reiff et al., 1977; 1980; Cowley, 1982, Gosling et al., 1990a, b, c; 
a) $B_{y}=B_{y 1}<0$ (N. hemisphere)

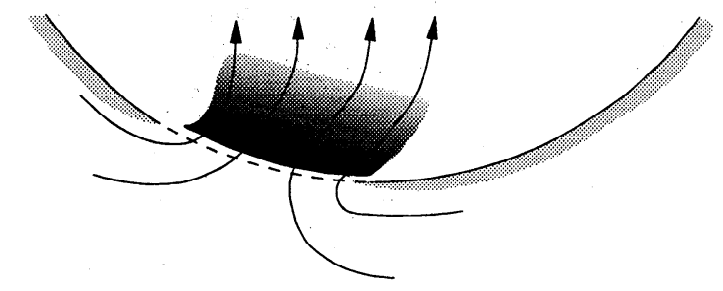

b) $B_{y}=B_{y 2}<B_{y 1}<0$
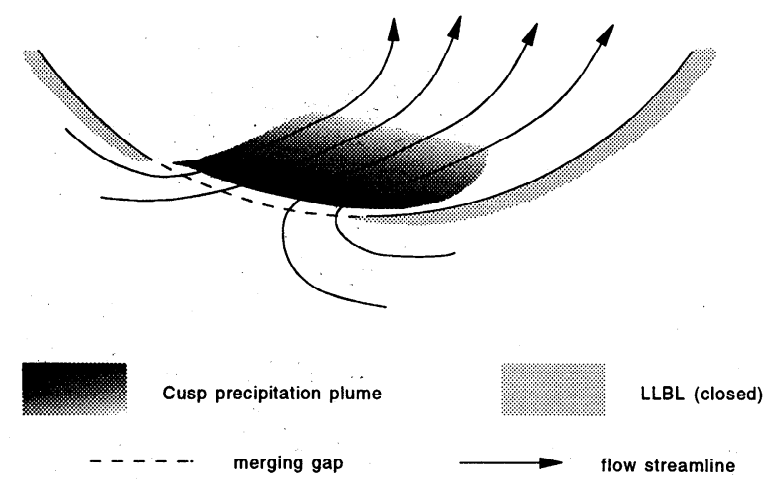

Figure 1. Plasma flow streamlines (arrows) and the regions of $630-\mathrm{nm}$ dominant emission (shaded) in the northern hemisphere for negative magnetosheath $B_{y}$. (a) small $\left|B_{y}\right|$; (b) larger $\left|B_{y}\right|$. The dashed line shows the (static) merging gap, the ionospheric projection of the magnetopause reconnection neutral line. Other ("adiaroic") parts of the open/closed boundary are shown as a solid line at the poleward edge of the closed LLBL. The graduated shaded region is the "cusp plume" region of $630-\mathrm{nm}$ emission on newly opened field lines (as precipitation evolves from open LLBL to cusp to mantle) the region shaded uniform grey is any $630-\mathrm{nm}$ emission due to precipitation from a closed LLBL. The northward direction is up the page and east is to the right.

Smith and Rodgers, 1991; Fuselier et al., 1991; Paschmann, 1984; Paschmann et al., 1979, 1986, 1990; Sonnerup et al., 1981, 1990; Maynard et al., 1991; Sanchez et al., 1990; Sanchez and Siscoe, 1990]. The near-zero pitch angle ions injected across the magnetopause on the dayside, i.e., via the rotational discontinuity on newly opened flux tubes, reach middle or even low altitudes, where they are classified as "cleft" (here meaning the open field line part of the lowlatitude boundary layer) or "cusp" if densities are higher. Plasma injected across the tail lobe boundary on the nightside (into the high-altitude mantle region) has a large antisunward bulk flow and only a few ions have Earthward velocities: by the time that such ions (with weak accompanying electron precipitation) reach low altitudes the field line has convected into the polar cap and this plasma forms a low-density polar cap precipitation. Between the cusp and the polar cap the plasma characteristics at low altitudes evolve through a region also termed "mantle" (although very few of these particles have come from the high-altitude mantle because of the effect of antisunward convection) [Cowley et al., 1991b]. The evidence that magnetosheathlike plasma at low altitudes is on newly opened field lines has recently been reviewed by Lockwood and Smith [1994].
Consequently, high-density, magnetosheathlike precipitation is expected in exactly the same location (i.e., on newly opened field lines) as the longitudinal flow which results when the magnetosheath field has a nonzero $B_{y}$ component [Cowley et al., 1991a]. This has recently been confirmed by de la Beaujardiere et al. [1993], using DMSP satellite data in conjunction with Sondrestromfjord radar data, and by Taguchi et al. [1993], who showed that the field-aligned currents associated with the longitudinal flow were on the poleward and equatorward edges of the "cleft/cusp" region. Both the ions and the electrons of this magnetosheathlike plasma precipitation cause red-line auroral emissions from $\mathrm{F}$ region altitudes [Mantas and Walker, 1976; Wickwar et al., 1974; Rees and Roble, 1986]. An important excitation mechanism for these emissions is the elevation of the temperature of the ionospheric electron gas in response to the precipitation [Titheridge, 1976; Wickwar and Kofman, 1984, Brace et al., 1982; Waterman et al., 1992, 1994]. The highenergy tail of the thermal electron gas can then excite significant numbers of atomic oxygen atoms to the $O^{1}(D)$ state which subsequently decay with the emission of $630-\mathrm{nm}$ photons [Kozyra et al., 1990; Lockwood et al., 1993c]. Hence excitation of $\mathrm{O}^{1}(\mathrm{D})$ state of atomic oxygen (which leads to $630 \mathrm{~nm}$ emission after a radiative lifetime averaging 1-2 min) will also be on the same newly opened field lines as the region of longitudinal flow caused by the field line curvature force.

In figure 1 , the region of high-density magnetosheath plasma precipitation labelled the "cusp plume" is shaded with a graduated grey (the graduation roughly denotes elapsed time since the field line was reconnected). We do not compare with satellite measurements of particle data, and hence it is not necessary to specify the relationship of this region to the various classifications of precipitation devised by Newell et al. [1991] (LLBL/cleft, cusp, mantle, and polar cap). However, we do study ground-based observations of $630-\mathrm{nm}$ emissions, and the shaded cusp plume region is where we predict detectable $630-\mathrm{nm}$ emission due to magnetosheathlike plasma precipitation to low altitudes down newly opened field lines. Notice that an LLBL/cleft population on open field lines (as observed by Gosling et al. [1990a, b, c] Smith and Rodgers [1991] and Fuselier et al. [1991]) would precipitate within this "cusp plume" region. In addition, there may be $630-\mathrm{nm}$ emission from a second type of LLBL/cleft population on closed field lines. Such a region is shown in Figure 1 by the constant light grey shading. This closed LLBL/cleft is taken as not extending across the merging gap; i.e., it is assumed that at the MLT of the merging gap the processes which populate such a closed LLBL with magnetosheathlike plasma are too slow to compete with the average rate at which it is eroded by reconnection.

In Figure 1a, the magnetosheath $B_{y}$ component is relatively weak, giving weak longitudinal flow. The flow streamlines are therefore aligned only slightly to the duskward side of polcward and 630-nm emission will be seen in a region (shaded) which extends with the convection streamlines slightly to the east of north from the merging gap.

Figure $1 \mathrm{~b}$ shows the situation when the magnetosheath $B_{y}$ component has increased in magnitude (and is still negative), but the reconnection voltage has remained constant, such that the antisunward convection component is the same as in Figure 1a. The larger tension force causes larger azimuthal 
flow in the sunward part of the polar cap, and hence flow streamlines there are directed more toward dusk. Hence the cusp plume region of $630-\mathrm{nm}$ emission on newly-opened field lines extends more toward dusk than in Figure 1a.

Newell and Sibeck [1993] suggest that the quasi-periodic flow bursts seen in dayside auroral transients are simply caused by increases in the magnitude of the magnetosheath $B_{y}$ component. This new interpretation has clear implications for the behavior of the region of $630-\mathrm{nm}$ emission which must periodically move back and forth between the two positions shown in Figure 1, with each cycle of $\left|B_{y}\right|$, and hence with each longitudinal flow burst. Because Newell and Sibeck do not consider any changes in the reconnection rate, the newly opened field lines are produced at the same rate and the region of $630-\mathrm{nm}$ emission will be continuously present (because the reconnection continuously generates new open flux) but will move with the flow streamlines in response to the changes in $B_{y}$. As the magnitude of the (negative) magnetosheath $B_{y}$ component increases at the start of the longitudinal flow burst, the 630 -nm-luminous region will migrate duskwards, toward the orientation in Figure $1 \mathrm{~b}$. Conversely, as th $2 \mathrm{Ffe} B_{y}$ component decreases again at the end of the azimuthal flow burst, the region will return toward the orientation in Figure 1a. Hence pulsing the magnetosheath $B_{y}$ will cause longitudinal flow bursts (provided the pcriod is sufficiently long to allow ionospheric response), and these will cause the continuously present cusp plume region of magnetosheathlike precipitation to "wag" back and forth in the east-west direction [Lockwood et al., 1994].

A complication mentioned, but not invoked, by Newell and Sibeck [1993] is that the changing magnetosheath $B_{y}$ may cause the merging gap to migrate in longitude. Observations of the cusp indicate that for the more negative $B_{y}$ in Figure $1 \mathrm{~b}$, the merging gap would shift westward, toward dawn (see review by Cowley et al. [1991a, and references therein]). In this case the cusp plume would distort, as in Figure 1b, but would also shift as a whole to the west with the merging gap. The flux tubes, however, would at all times convect east due to the magnetic tension force. Therefore this would cause the phase motion of the 630-nm-luminous patch to differ from the motion of the flux tubes within it. This does not agree with observations of dayside auroral transients within which the plasma flow velocity has been found to be in close agreement with the phase velocity of the events, at all stages of their evolution [Sandholt et al., 1990; Lockwood et al., 1990, 1993; Elphic et al., 1990]. Hence, like Newell and Sibeck [1993], we do not 'consider this complication further.

\section{Ionospheric Effects of Pulsed Reconnection}

In this section, we repeat the predictions of the location of the $630-\mathrm{nm}$ aurora and of the ionospheric convection (corresponding to Figure 1) for the second model of pulsed reconnection with a steady magnetosheath $B_{y}$. This model was previously shown to be consistent with a number of 630 nm events with dayside flow events by Lockwood et al. [1989a, b, 1990, 1993a, b, c], Sandholt et al. [1990, 1993a, b], Elphic et al., [1990] and by Moen et al. [1995]. In this model, the increase in the reconnection rate produces newly opened flux tubes more rapidly, but (in the absence of changes in magnetosheath conditions) each newly opened flux tube evolves in almost the same manner away from the merging gap. The ionosphere is incompressible, hence an increase in the reconnection rate causes an increase in the area of the region of newly opened flux. For the case of pulses of reconnection rate over a nonzero background (the general case of the pulsating cusp model [Smith et al., 1992]), the latitudinal thickness of the region of longitudinal flow and $630-\mathrm{nm}$ emission increases in response to the reconnection pulse, after the merging gap (dashed line) has eroded equatorward, as described by Iockwood et al. [1993b, c]. The transient increase in the width of that region moves east/west under the magnetic curvature force on each newly opened flux tube which makes up the region: it also drifts poleward as the magnetosphere-ionosphere system (and hence the polar cap boundary) returns toward an equilibrium configuration. The broadened $630-\mathrm{nm}$ emission region is accompanied by a broadened region of rapid longitudinal flow.

The effects of one isolated pulse in the reconnection rate (over a steady background level) are shown in Figure 2, using the same format, symbols and shading as in Figure 1. Figure $2 a$ shows the cusp plume and flows resulting from the background reconnection with strongly negative magneto-
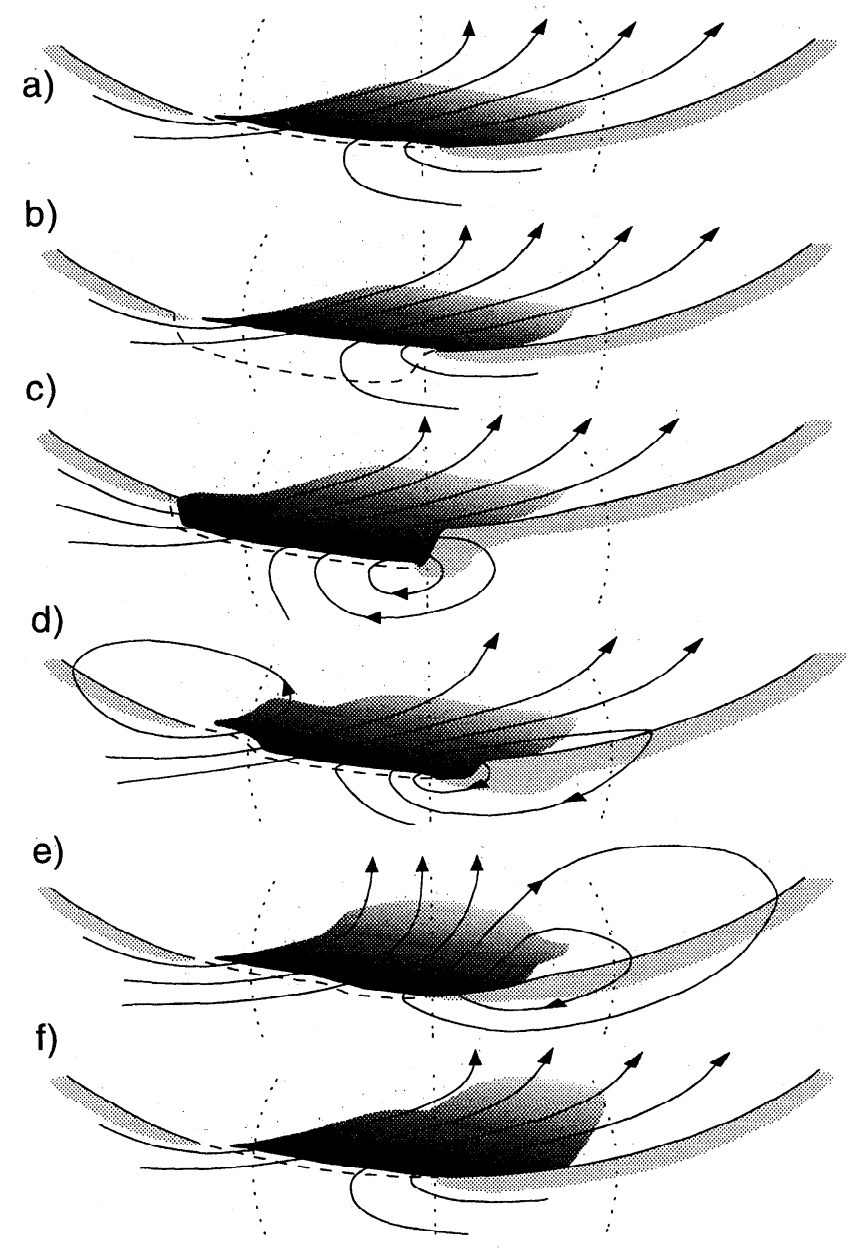

Figure 2. The evolution of plasma flow streamlines and regions of $630-\mathrm{nm}$ emission following a single pulse of enhanced magnetopause reconnection rate over a steady background value. Symbols are shadings are as for Figure 1. The dotted lines show the magnetic meridian and segments of the $60^{\circ}$ zenith angle circle for an observing site close to the eastern end of the merging gap. 
sheath $B_{y}$, as in Figure $1 \mathrm{~b}$. In Figure $2 \mathrm{~b}$ a pulse of enhanced reconnection rate has moved the merging gap equatorward, but as this has taken place on a time scale shorter than the travel time from the magnetopause of either cusp ions or Alfven waves, the 630 -nm aurora and flows have yet to be altered. (Significant fluxes of electrons dn not precipitate until the ions arrive, such that quasi-neutrality is maintained). In Figure 2c, cusp/(open)LLBL particles start to arrive on the newly opened field lines produced by the reconnection pulse, which also begin to move eastward under the action of magnetic tension. The pattern of convective flows at this and subsequent times is as predicted by the model of Cowley and Lockwood [1992], as described by Cowley et al. [1991] and Lockwood et al. [1993c]. In Figures 2d-2f, the patch of newly-opened flux produced by the reconnection pulse migrates east and also moves increasingly poleward: in Figure $2 \mathrm{f}$ the flows are returning to their pre-event form and the extra latitudinal width of the 630 -nm-emitting region is fading as the field lines opened by the pulse become appended to the tail lobe. The situation subsequently returns to that shown in Figure 2a, provided there is not a second pulse of enhanced reconnection.

Because the $B_{y}$ component is constant, all newly opened field lines inside the region of $630-\mathrm{nm}$ emission experience roughly the same eastward flow due to the tension force. In this case of reconnection which is continuous (i.e., the reconnection never falls to zero) but showing pulsed enhancements in rate, the longitudinal flow bursts seen at EISCAT are equatorward expansions of the region of fast eastward flow (caused by the equatorward motion of the open/closed boundary in response to the reconnection pulse). Note that Figure 2 presents this general case of "pulsed but continuous" reconnection, for which a channel of peak eastward flow is always present. The corresponding predictions for the special case where there is no background reconnection between the pulses ("fully-pulsed reconnection") have been presented by Cowley et al. [1991b] and Lockwood et al. [1993c]. In this special case, the eastward flow would decay between the events, on the timescale of the decay of the tension force on the last flux tubes to be opened by the pulse decays.

\section{Observations on January 20, 1990}

We present observations made on January 20, 1990, using optical instruments on Svalbard, along with simultaneous observations by the EISCAT UHF radar. Figure 3 shows the field of view of the 630-nm all-sky camera at Ny Ålesund, $\mathrm{N} \AA$, with concentric circles representing zenith angles of $30^{\circ}$ and $60^{\circ}$, the perpendicular axes denoting the geographic north-south and east-west directions (north is to the top and east is to the right). The inclined dashed axis (M) is the magnetic meridian. The points marked $\mathrm{P}$ and $\mathrm{Q}$ on the figure are the centres of range gates 15 and 19 of the SP-EI-POLI experiment, in which incoherent scatter radar signals are transmitted and received by the EISCAT UHF radar at Troms $\varnothing$ [see Willis et al., 1986; Lockwood 1991]. In this experiment, the radar cycles between two beam directions, dwelling $2 \mathrm{~min}$ at each and completing each cycle in $5 \mathrm{~min}$. The pulse length employed gives scattering volumes $37.5 \mathrm{~km}$ long, and the 0.5-degree beamwidth of the UHF antenna means that these have a circular cross section of roughly 12 $\mathrm{km}$ diameter for the ranges considered here. The gating of the receiver divides each beam into 24 such scattering

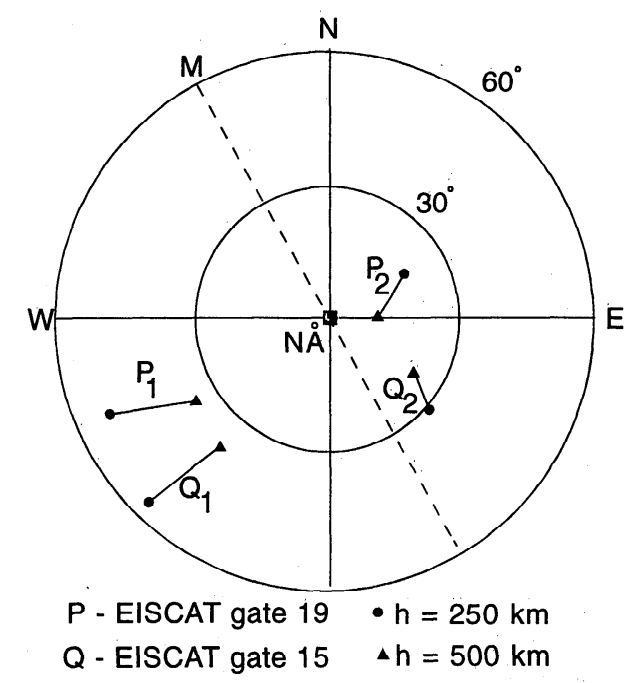

Figure 3. Field of view of the $630-\mathrm{nm}$ all-sky camera at $\mathrm{Ny}$ Allesund (NÅ). The geographic north, west and east directions are marked $\mathrm{N}, \mathrm{W}$ and $\mathrm{E}$ and the dashed line $\mathrm{M}$ is the magnetic meridian. The circles are zenith angles of $30^{\circ}$ and $60^{\circ}$ from $N \AA$. The points marked $P_{1}$ and $P_{2}$ are the centers of the EISCAT range gate 19 for azimuth 1 and 2, respectively, of the EISCAT POLI experiment (see Tables 1 and 2); $\mathrm{Q}_{1}$ and $\mathrm{Q}_{2}$ are the corresponding points for gate 15 . These points are mapped assuming emission altitudes of $630-\mathrm{nm}$ luminosity of $250 \mathrm{~km}$ (circles) and $500 \mathrm{~km}$ (triangles) on the field line intersecting the center of the EISCAT range gate.

volumes or "range gates." The pair of points labelled $\mathrm{Q}_{1}$ refers to the center of gate 15 for azimuth $1\left(332^{\circ}\right.$ east of north) of the POLI experiment, $Q_{2}$ refers to gate 15 for azimuth $2\left(356^{\circ}\right)$. Similarly, $\mathrm{P}_{1}$ and $\mathrm{P}_{2}$ refer to gate 19 for azimuths 1 and 2 , respectively. The choice of these two range gates was determined by the location of $630-\mathrm{nm}$ luminosity, as will be described below.

In Figure 3, these two EISCAT range gates are mapped onto the $630-\mathrm{nm}$ camera field of view for two different assumptions about the height of $630 \mathrm{~nm}$ emission. In the first case (solid circles), the magnetic field line threading each range gate center is mapped down to an assumed 630-nm emission altitude of $250 \mathrm{~km}$, and the azimuth and elevation of that emission point at the Ny Alesund camera site are then computed. In the second case, the field line is mapped to 500 $\mathrm{km}$ (solid triangles). The mapping is done using the IGRF magnetic field model with coefficients for 1990 . It can be seen that the assumed emission altitude has considerable implications for the mapped position of the radar range gate, especially for larger zenith angles. Gate 19, with the radar beam at azimuth 2, is the closest to the Ny Alesund site, and for such small zenith angles the altitude of emission has a smaller effect on the mapping. Table 1 gives the coordinates of these points and Table 2 gives the zenith angles and azimuths at $\mathrm{Ny}$ Ålesund $\left(78.92^{\circ} \mathrm{N}, 11.95^{\circ} \mathrm{E}\right)$ for emission heights of 250 and $500 \mathrm{~km}$ along the field line intersecting the EISCAT range gates.

These mappings can only be regarded as approximate. The 630-nm photons are emitted by excited oxygen atoms, after a radiative lifetime during which they drift with the neutral wind velocity $\underline{V}_{n}$ from the point at which they are excited. Given $V_{n}$ is typically $0.5 \mathrm{~km} \mathrm{~s}^{-1}$ and the mean lifetime of the 
Table 1. Locations of the Centers of EISCAT Gates

\begin{tabular}{cccccccc}
\hline $\begin{array}{c}\text { Gate } \\
\text { Number }\end{array}$ & $\begin{array}{c}\text { Azimuth } \\
\text { Number } \\
\text { (Figure 2) }\end{array}$ & $\begin{array}{c}\text { Point } \\
\text { Label }\end{array}$ & $\begin{array}{c}\text { Geographic } \\
\text { Latitude, } \\
\text { deg }\end{array}$ & $\begin{array}{c}\text { Geographic. } \\
\text { Longitude, } \\
\text { deg }\end{array}$ & $\begin{array}{c}\text { Range, Height, } \\
\text { r, } \\
\mathrm{km}\end{array}$ & $\begin{array}{c}\text { h, } \\
\mathrm{km}\end{array}$ & $\begin{array}{c}\text { Latitude, } \\
\text { deg }\end{array}$ \\
\hline 15 & 1 & $\mathrm{Q}_{1}$ & 76.30 & 2.81 & 1050 & 453 & 75.16 \\
15 & 2 & $\mathrm{Q}_{2}$ & 77.76 & 16.54 & 1050 & 453 & 74.92 \\
19 & 1 & $\mathrm{P}_{1}$ & 77.06 & 359.49 & 1200 & 529 & 75.98 \\
19 & 2 & $\mathrm{P}_{2}$ & 78.83 & 15.90 & 1200 & 529 & 76.03 \\
\hline
\end{tabular}

Longitude measured positive east

excited state is roughly $1 \mathrm{~min}$ for $250 \mathrm{~km}$ altitude and $110 \mathrm{~s}$ for greater altitudes (around $500 \mathrm{~km}$ ), the point of emission will typically be $30-60 \mathrm{~km}$ downwind from the point of excitation. This provides a more fundamental limit to the accuracy of the mapping than the magnetic field model. In addition, the luminosity seen at any one elevation and azimuth is an integration along the line of sight which traverses a range of field lines within the height range of $630-\mathrm{nm}$ emission. Conversely, emissions from a range of altitudes along any one field line contributes to luminosity over a linear segment of the camera field of view.

\section{The 630 nm All-Sky Camera Observations}

Plate 1 shows a sequence of images, 1 min. apart, recorded by the 630-nm all-sky camera at Ny Alesund on January 20,1990. The concentric circles and axes are as in Figure 3. The observations presented commence at $0930 \mathrm{UT}$, which is a magnetic local time of approximately 1230 MLT for the Ny Alesund field line. To help identify events in these images, Figure 4 presents two luminosity contours scaled from four selected frames of Plate 1. The isophotes chosen are for relative intensities (in arbitrary units) of $R_{i}=$ 94 (the contour separating green and yellow in Plate 1) and $R_{i}=184$ (the contour separating light blue and orange). In Figure 4, the circle is the $60^{\circ}$ zenith angle and the dot the Ny Alesund site, the diameter shown is the magnetic meridian (M in figure 3). The dashed lines are the boundaries (at $R_{i}$ = 94) at 0951 UT, when there appcars to be no significant event present: hence comparison of the solid and dashed lines aids the identification of events. It is interesting to note that this background does not extend to the eastern horizon of the camera field of view. The first event in Plate 1 is clearly present by 0931 UT (Figurc 4a). The lcading edgc of the eastward moving event (denoted $\mathrm{L}$ ) is marked by a poleward expansion of the poleward $R_{i}=94$ contour, closely followed by the onset of intensities exceeding the upper $\left(R_{i}>184\right)$ contour in the center of the band. This leading edge propagates to the east has crossed the magnetic meridian by 0935 UT (Figure 4b). By this time, a trailing edge (denoted T) can be seen following $\mathrm{L}$ eastward. This is marked by an equatorward return of the poleward $R_{i}=94$ contour and a nearsimultaneous decay in the peak intensities in the band (to $R_{i}$ below 184). The decay in peak intensities does not migrate east with $\mathrm{T}$ at the lowest latitudes, but does at the higher latitudes, hence the region bounded by the upper contour skews with time. The trailing edge straddles the magnetic meridian by 0939 UT (Figure 4c) when the skewed bright region $\left(R_{i}>184\right)$ has broken into two peaks, one to the northeast of Ny Ålesund, and an extended one running along the L-shells to the south of Ny Allesund (and this is in the process of separating into two spots prior to fading). As there is nearly always a weak minimum in $R_{i}$ at zero zenith angle, at least some of this structure in the highest intensities appears to be consistent with the effect of the zenith angle on the slant path through the 630-nm-luminous region. By 0943 UT (Figure 4d), this first event has faded on the eastern horizon and a new event is emerging around the magnetic meridian and Plate 1 shows that almost the same sequence subsequently repeats.

Table 2. Azimuth and Zenith Angles at Ny Ålesund

\begin{tabular}{|c|c|c|c|c|c|c|c|c|c|c|c|}
\hline \multirow{2}{*}{$\begin{array}{l}\text { Gate } \\
\text { Number }\end{array}$} & \multirow{2}{*}{$\begin{array}{l}\text { Azimuth } \\
\text { Number } \\
\text { (Figure } \\
\text { 2) }\end{array}$} & \multirow{2}{*}{$\begin{array}{l}\text { Point } \\
\text { Label }\end{array}$} & \multirow{2}{*}{$\begin{array}{l}\text { Invariant } \\
\text { Latitude } \\
\text { deg }\end{array}$} & \multicolumn{4}{|c|}{ Emission height of $250 \mathrm{~km}$} & \multicolumn{4}{|c|}{ Emission height of $500 \mathrm{~km}$} \\
\hline & & & & $\begin{array}{c}\text { Geographic } \\
\text { Latitude, } \\
\text { deg }\end{array}$ & $\begin{array}{c}\text { Geographic } \\
\text { Longitude, } \\
\text { deg }\end{array}$ & $\begin{array}{l}\text { Zenith, } \\
\text { deg }\end{array}$ & $\begin{array}{c}\text { Azimuth, } \\
\text { deg } \dagger\end{array}$ & $\begin{array}{c}\text { Geographic } \\
\text { Latitude, } \\
\text { deg }\end{array}$ & $\begin{array}{c}\text { Geographic } \\
\text { Longitude, } \\
\text { deg }\end{array}$ & $\begin{array}{l}\text { Zenith, } \\
\text { deg }\end{array}$ & $\begin{array}{c}\text { Azimuth, } \\
\text { deg } \dagger\end{array}$ \\
\hline 15 & 1 & $Q_{1}$ & 75.16 & 76.57 & 2.61 & 55.87 & 224.70 & 76.245 & 2.86 & 39.03 & 220.66 \\
\hline 15 & 2 & $Q_{2}$ & 74.92 & 78.01 & 16.52 & 30.93 & 123.58 & 77.70 & 16.55 & 20.29 & 122.53 \\
\hline 19 & 1 & $\mathrm{P}_{1}$ & 75.98 & 77.40 & 359.13 & 55.45 & 246.4 & 77.10 & 359.45 & 36.00 & 238.14 \\
\hline 19 & 2 & $\mathrm{P}_{2}$ & 76.03 & 79.20 & 15.84 & 19.88 & 68.96 & 78.92 & 15.89 & 10.05 & 85.56 \\
\hline
\end{tabular}

* Longitude measured positive east.

$\dagger$ Azimuth measured east of north. 


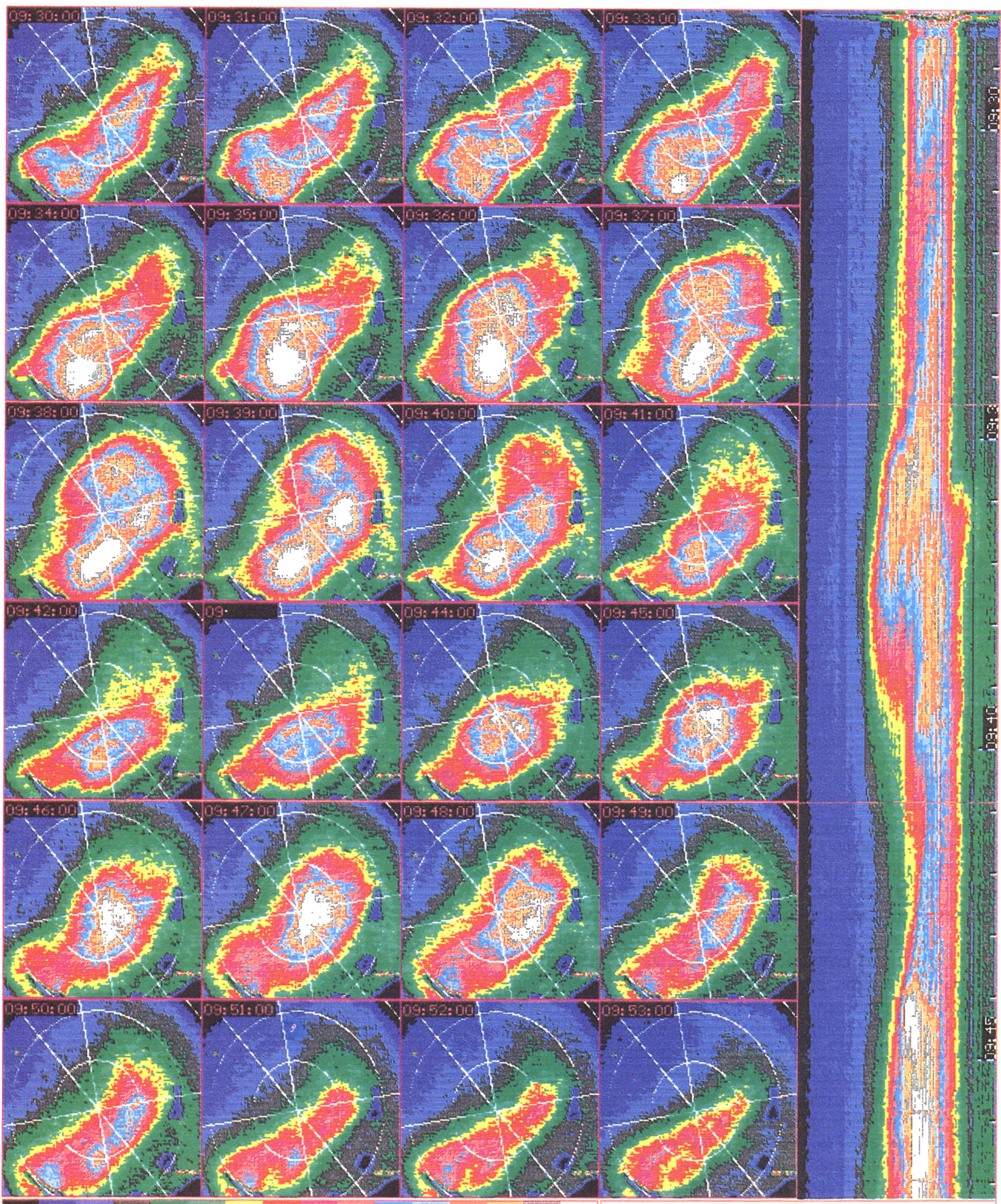

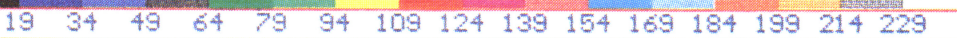

Plate 1. Sequence of 1-sec integrated images, 1 minute apart, observed by the 630 -nm all-sky camera at Ny Ålesund on January 20,1990. The axes and concentric circles are as in Figure 3. The panel to the right shows the $630-\mathrm{nm}$ luminosity observed along the magnetic meridian (M) as a function of zenith angle (polewrd to the left) and universal time (running from top to bottom). 
a). 09:31

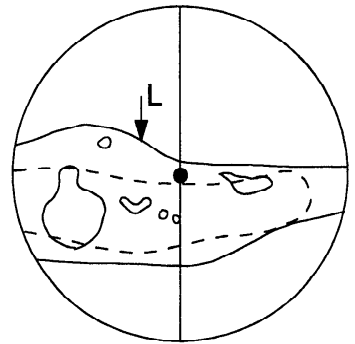

b). 09:35

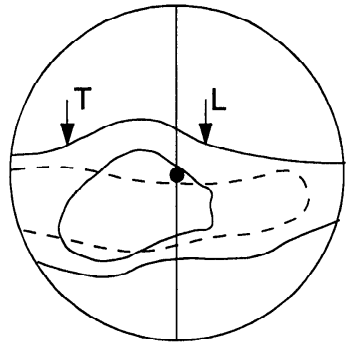

c). 09:39

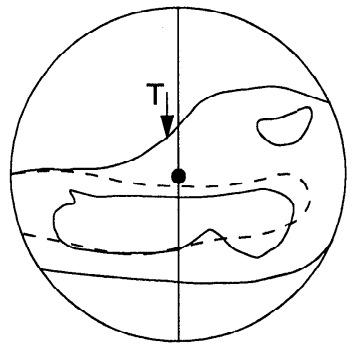

d). 09:43

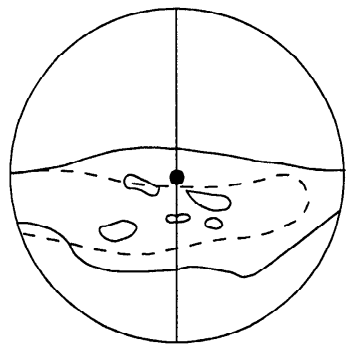

09:51

Figure 4. Contours of relative $630-\mathrm{nm}$ intensity $\left(\mathrm{R}_{\mathrm{i}}=94\right.$ and 184 in Plate 1) for four times, four minutes apart, taken from Plate 1: (a) 09:31; (b) 09:35; (c) 09:39 and (d) 09:43. In each case, the dashed lines are the $\mathrm{R}_{\mathrm{i}}=94$ contours for 09:51 UT. The dot is the Ny Ålesund site, the circle marks $60^{\circ}$ zenith angle from that site and the vertical diameter is the magnetic meridian. The leading and trailing edges of eastward-moving events identified from Plate 1 are marked $\mathrm{L}$ and $\mathrm{T}$, respectively.

The first event is first seen at about 0930 UT. Inspection of the 1-second images between 0940 and 0941 UT (not shown) does indicate that the event fades, with its western half still within the camera field of view, rather than propagating out of the field of view to the east. Either way, we can say that the event lasts at least $10 \mathrm{~min}$. This duration is of the same order as the interval for which cusp precipitation will last on each newly opened field line, as calculated from cusp ion dispersion by Lockwood and Davis [1994] and modelled theoretically by Lockwood and Smith [1994]. However, we should note that precipitation evolves from "cleft" to "cusp" to "mantle" as the newly opened field line evolves [Cowley et al., 1991b; Lockwood et al., 1993a] and that the cleft and mantle precipitations will also result in some $630-\mathrm{nm}$ emission, that in the mantle region fading as the field line evolves. Therefore the fading of the event below a certain luminosity threshold will not in general correspond to the precipitation on any one newly opened field line evolving through the threshold criteria used to separate the precipitations termed cusp and mantle. Nevertheless, if the lower limit of 10 minute applies for the lifetime of these events, we could conclude that for much or all of their lifetime they are caused by precipitation which is termed "cusp." However, the events may last longer than this, indicating that "mantle" precipitations may contribute (later in the event lifetime). Note also that "LLBL/cleft" precipitation on the most recently opened field lines will also contribute briefly early in the event lifetime (and along its equatorward edge).

The trailing edge of the first event is at zenith angles of $60^{\circ}, 30^{\circ}$, and $0^{\circ}$ (along the Ny Allesund L-shell) at about 0932, 0938 and 0940 UT, respectively. For an assumed emission altitude of $250(500) \mathrm{km}$, these timings give approximate eastward phase motion speeds of $0.8(1.6) \mathrm{km}$ $\mathrm{s}^{-1}$ and $1.2(2.4) \mathrm{km} \mathrm{s}^{-1}$.

A similar sequence is observed between 0941 and 0950 UT as a second, somewhat smaller, event propagates eastward with similar velocity. At every phase of its evolution it is roughly $10 \mathrm{~min}$ after the corresponding phase of the first event. This period is typical of the full sequence of events seen on this day and in the survey by of many polewardmoving dayside auroral events by Fasel (submitted manuscript, 1994).

\section{EISCAT Radar Observations}

From Figure 3 and Plate 1, it can be seen that between events, gate 19 of the EISCAT radar is close to the poleward edge of the $630-\mathrm{nm}$ band, but is engulfed by the transient events (between $\mathrm{T}$ and $\mathrm{L}$ in Figure 4) as they move over it. Meanwhile, gate 15 is always quite close to the equatorward edge of the of band of $630-\mathrm{nm}$ aurora. In this paper, we are concerned with the plasma flows within and around the events. At these large ranges from the EISCAT site at Troms $\varnothing$ (see Table 1), it is not possible to combine line-ofsight velocities to generate accurate flow vectors, although they do reveal the flow in the bursts is eastward and poleward. Hence we use a scalar observation of the line-of-sight ion temperature to infer the magnitude of the flows. Figures 5 and 6 show the line-of-sight ion temperatures observed at
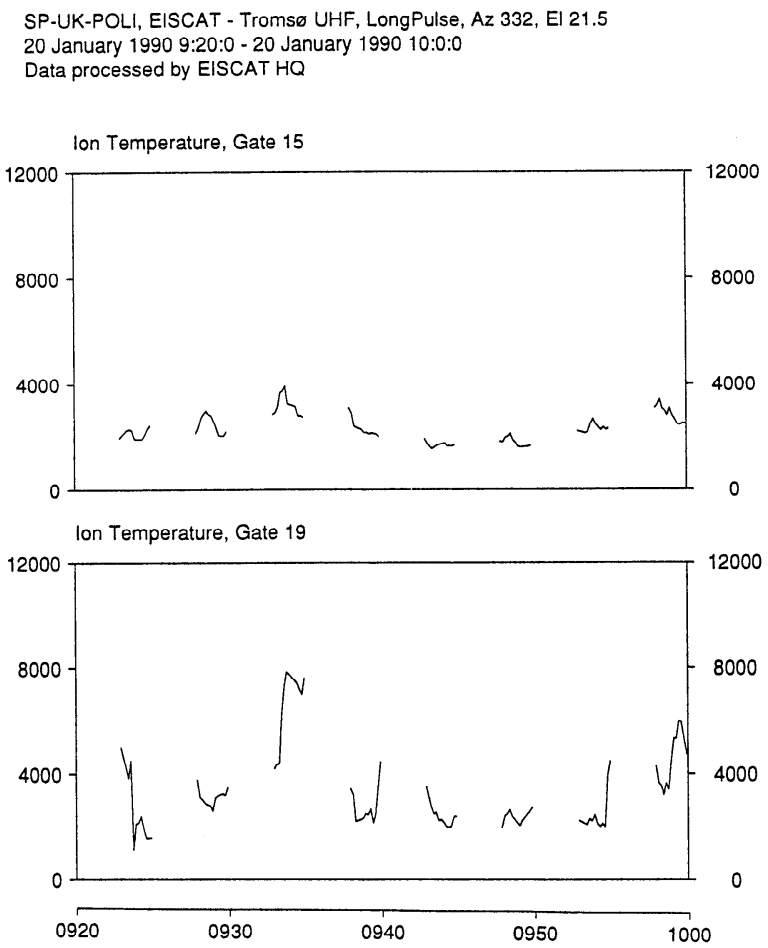

Figure 5. Ion temperatures $\left(\mathrm{T}_{\mathfrak{i}}\right)$ observed by EISCAT in gate 15 (upper panel) and 19 (lower panel) for azimuth 1 (i.e points $Q_{1}$ and $P_{1}$ in Figure 3, respectively) on January 20, 1990. The data are 10-second integrations and the radar dwells at this azimuth for $2 \mathrm{~min}$ in each 5-minute cycle of the POLI experiment. 
SP-UK-POLI, EISCAT - Tromsø UHF, LongPulse, Az 356, El 21.5 20 January 1990 9:20:0 - 20 January 1990 10:0:0

Data processed by EISCAT HQ

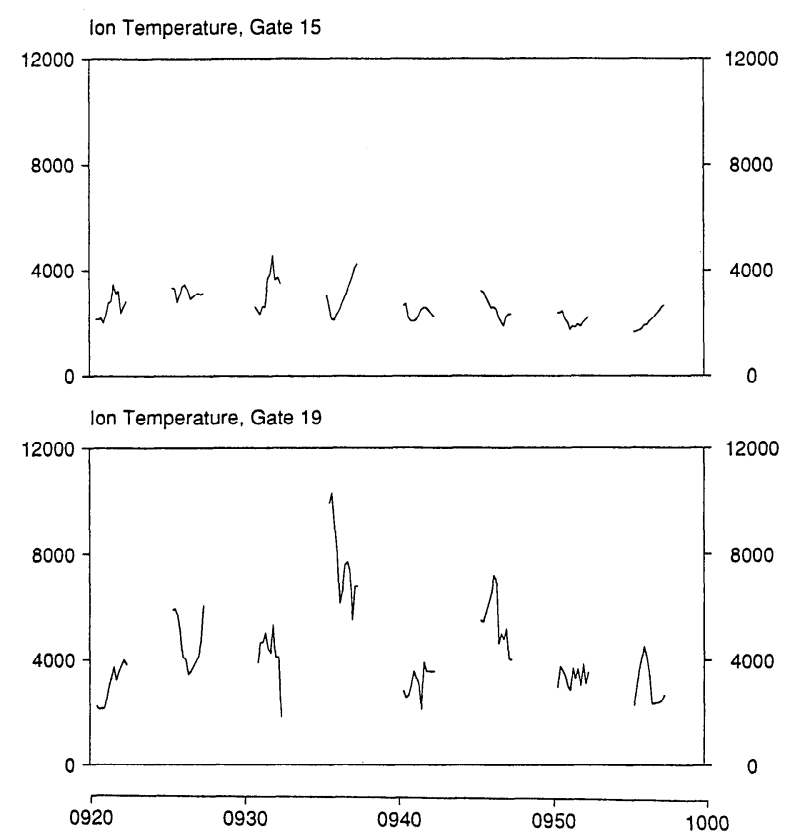

Figure 6. As for Figure 5, for azimuth 2 (points $\mathrm{Q}_{2}$ and $\mathrm{P}_{2}$ ).

gates 15 (top panel) and 19 (bottom panel) for azimuths 1 and 2 , respectively. At the altitudes of these observations (around $500 \mathrm{~km}$, see Table 1), ion-ion collisions render the ion velocity distributions almost isotropic, even when the ion-neutral frictional heating is strong [Tereshchenko et al., 1991; McCrea et al., 1993]. (At lower altitudes, the ion neutral collisions lead to an anisotropic non-Maxwellian distribution when the heating is strong). As a result, these line-of-sight ion temperatures are good estimates of the threedimensional ion temperature $T_{i}$ [Lockwood et al., 1993d], which obeys the thermal balance equation for the ion gas:

$$
\underline{\mathrm{V}_{i}}-\underline{\mathrm{V}}_{n} \mid=\left\{\left(T_{i}-T_{n}\right)\left(3 k / m_{n}\right)\right\}^{1 / 2}
$$

where $T_{n}$ is the neutral (exospheric) temperature, $m_{n}$ the mean mass of the neutral atmospheric gas particles (taken here to be pure $\mathrm{O}$ atoms), $k$ is Boltzmann's constant, $\underline{V}_{i}$ is the ion velocity vector and $\underline{V}_{n}$ is the neutral wind vector. This equation neglects minor terms, the largest of which is ionelectron conduction. In the observed events, electron temperatures are elevated, mainly by an inferred soft electron precipitation source, to around $4500 \mathrm{~K}$. Because the ion temperatures are greater $\left(T_{i}>5500 \mathrm{~K}\right)$, the ion gas is cooled rather than heated by this conduction. It should be noted that the derived values of $T_{i}$ assume that the ion gas is $\mathrm{O}^{+}$, any molecular ions at the observed altitude during heating events would cause $T_{i}$ to be underestimated [Lockwood et al., 1993d], and use of (1) would then cause an underestimation of $V_{i}$. We estimate $T_{n}$ from the minimum ion temperatures seen in Figures 5 and 6 to be about $2000 \mathrm{~K}$.

Consider Figure 5 for azimuth 1. At 0932:30 UT, the ion temperature observed in gate 19 reaches $7500 \mathrm{~K}$, where it stays for the remainder of that antenna dwell. From (1) this implies an ion speed of $V_{i} \approx 2.9 \pm V_{n}$, where $V_{n}$ is typically of order $0.5 \mathrm{~km} \mathrm{~s}^{-1}$. A weak peak in ion temperature $(\approx 3800$
$\mathrm{K}$ ) is seen at about the same time at gate 15 . A second peak may have been present at gate 19 around 0942:30 UT (when the radar is pointing along the other azimuth), as the ion temperature is seen to rise immediately before this data gap and decrease immediately after it.

For azimuth 2 (Figure 6), gate 19 shows two clear peaks in $T_{i}$, at 0935 and 0946:18 UT. Averaged over the relevant dwells, these two events give ion temperatures of $7500 \mathrm{~K}$ and $5820 \mathrm{~K}$, which by (1) yield ion speeds of $V_{i} \approx 2.9 \pm V_{n}$ and $V_{i} \approx 2.4 \pm V_{n}$. As for azimuth 1 , gate 15 shows only relatively weak enhancements over the inferred value of $T_{n}$.

It is important to compare the times of these flow bursts, revealed by their effect upon the ion temperatures observed at gate 19 , relative to the passage of the associated $630-\mathrm{nm}$ transient. For first event at azimuth 1, the ion temperature rises steeply in the interval 0931:30-0932:30 UT. From the optical data, the center of the leading edge $(\mathrm{L})$ of the first transient expands over this gate $\left(\mathrm{P}_{1}\right)$ around 0929 (0931) UT for assumcd cmission altitude of $250(500) \mathrm{km}$, corrcsponding to mean excitation times of 0928 and 0929 UT, respectively. (For an altitude of $250 \mathrm{~km}$, the mean radiative lifetime of the excited state is roughly $1 \mathrm{~min}$, whereas for $500 \mathrm{~km}$, it is nearer $2 \mathrm{~min}$ ). Hence the main flow burst commences roughly $3 \mathrm{~min}$ after the increase in the local precipitation. Similarly, the same event, seen at the other azimuth, causes a steep rise in ion temperature in the data gap at 0932:300935:00 UT. For either emission altitude, the center of the leading edge $(\mathrm{L})$ of the $630-\mathrm{nm}$ auroral event engulfs this gate $\left(\mathrm{P}_{2}\right)$ at about $0935 \mathrm{UT}$, corresponding to mean excitation times of 0934 and 0933 UT for peak emission altitudes of 250 and $500 \mathrm{~km}$, respectively. Hence, at this azimuth the flow burst onset is at some time between $1.5 \mathrm{~min}$ before and $2.5 \mathrm{~min}$ after the estimated onset of precipitation.

By the time the radar returns to azimuth 1 at $0938 \mathrm{UT}$, the flow burst has ceased and Plate 1 shows that the tail end of the optical event passes $P_{1}$ at about 0935:30 (0936:30) UT, for emission altitudes of $250(500) \mathrm{km}$., corresponding to last excitation times of about 0934:30 UT in both cases. Hence the flow burst is known to be over shortly after the precipitation has ceased. Similarly, the flow burst at $\mathrm{P}_{2}$ has ceased by the time the radar returns there at 0940 UT. The optical data show that the 630-nm transient fades there at about 0941 UT, corresponding to last mean excitation time of about 0939 (0938) UT for $250(500) \mathrm{km}$. Hence at both locations, the first flow burst event is within the period that the corresponding 630-nm transient event is excited.

The same sort of analysis of event timings can be applied to the second event. If the flow event is seen at azimuth 1 , it is in the period 0940-0943 UT. Figure 3 shows that the optical event forms very close to $P_{1}$, but is to the east of it (for either assumed altitude) by 0944 UT. The second event is, however, clearly observed at $P_{2}$ in the interval 0945-0947 UT but not before 0942 UT nor after 0950 UT. From Plate 1 , the second event passed over $P_{2}$ at about 0944-0950 UT, showing the exciting precipitation moved passed at 09430949 UT for $250 \mathrm{~km}$ or 0942-0948 UT for $500 \mathrm{~km}$. As for the first event, the second flow burst is coincident (in time and space) with the precipitation causing the $630-\mathrm{nm}$ aurora.

Gate 19 is the furthest which can be analyzed at 10-s resolution on January, 20 1990. At further ranges, information can only be obtained by post-integrating the data over the full 2-min dwell on the antenna. Sufficient signal-to-noise ratio to allow spectral analysis is obtained for gate numbers up to about 21. Figure 7 shows the ion temperatures 
observed in gates 11-21, from 2-min post-integrations of the data for azimuth 2 . For clarity, the grey-scaled pixels extend over the full 5-min cycles of the radar, but it should be remembered that the data are actually recorded in the first two minutes of each 5-min period. The two events are clearly seen as high ion temperature $\left(T_{i}>5500 \mathrm{~K}\right)$ in range gates 17-21 for the first event and 19-21 for the second event. Before, after and between the events, it can be seen that high ion temperatures were still present, but mainly in just one range gate.

Unfortunately, no IMF data were recorded at the time of these observations as IMP8 was in the magnetotail. The following section discusses two models of thee events which both require negative $\mathrm{IMF} B_{y}$ and $B_{z}$ components (in GSM coordinates), it should be noted that this IMF orientation is assumed and not measured.

\section{Discussion}

Could the Events be Caused by Magnetosheath $B_{y}$ Changes With a Steady Reconnection Rate?

In this section, we consider variations in the magnitude of the magnetosheath $B_{y}$ component (caused by either variations in IMF $B_{y}$ or by quasi-periodic compressions of the magnetosheath field by solar wind dynamic pressure changes) for steady magnetopause reconnection. To explain the observations on January 20,1990 , presented in the previous section, these fluctuations need to have repeat periods of about 10 min. The observations by Greenwald et al. [1990] show that the longitudinal ionospheric flow responds in full, even to a polarity change in $B_{y}$, over an interval of about $5 \mathrm{~min}$. Hence for these observed periods of $10 \mathrm{~min}$, the flow in the ionosphere will have a significant response to any $B_{y}$ changes. The flow streamlines and hence the "cusp plume" $630-\mathrm{nm}$ emission region would oscillate between the two situations shown in Figure 1. It is important to remember that for continuous reconnection (i.e., newly opened flux is
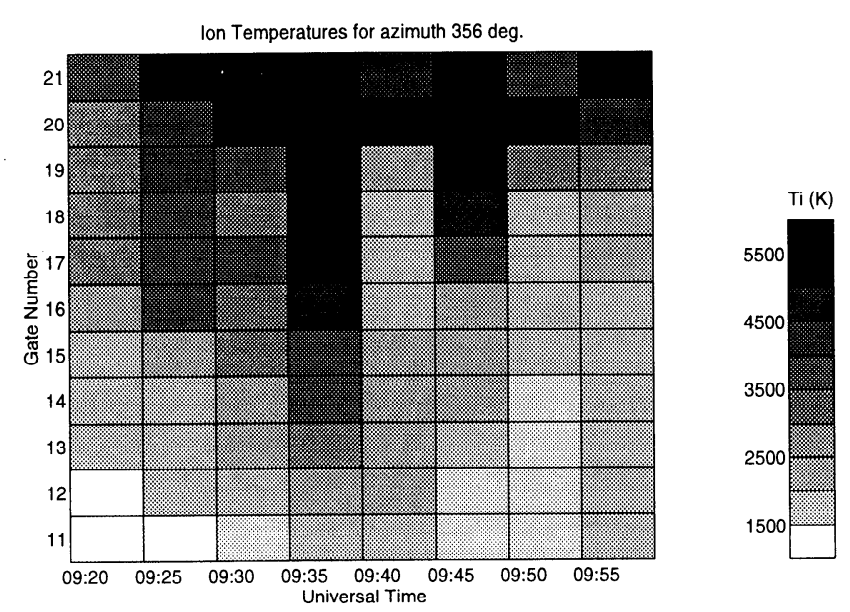

Figure 7. Grey-scale plot of ion temperatures $\left(T_{i}\right)$ derived from two-minute integrations of EISCAT data from azimuth 2 on 20 January 1990, shown as a function of gate number and universal time. Note that data are plotted to fill each 5min cycle of the experiment, but were actually recorded in the 2 min dwell at azimuth 2 at the start of each 5 -min period. generated continuously) the cusp plume patch of $630-\mathrm{nm}$ luminosity is continuously present. Each newly opened field line will show $630-\mathrm{nm}$ emission for the same length of time $(\tau)$ as it evolves away from the merging gap; i.e., if it experienced a constant convection speed, $v$, it will fade after it has moved a distance $(v \tau)$ from the merging gap. Hence if the reconnection rate is constant, the area of the region of cusp plume 630-nm luminosity would increase and decrease with the speed of the ionospheric flow. The poleward flow would remain roughly constant and hence the maximum poleward extent of the cusp plume would remain constant; however, its east-west extent would increase somewhat above the merging gap length as the eastward flow increased due to the magnetosheath $B_{y}$ becoming increasingly negative. Any closed LLBL/cleft aurora would be unaltered. What would be seen on the ground by an all-sky camera would depend on the relative size of the merging gap to the camera field of view.

If the merging gap was relatively short, a $630-\mathrm{nm}$ camera would image the whole of a continuous patch of $630-\mathrm{nm}$ emission in the cusp plume which would periodically move back and forth between the configurations shown in Figure 1. (The flow magnitude and hence, by (1) $T_{i}$, would peak when both eastern and western edges of the $630-\mathrm{nm}$ patch reached the most easterly location of their east-west oscillation). This cannot explain the events shown in Plate 1 because both east and west edges of the $630-\mathrm{nm}$ patches move eastward across the camera field of view, with no return westward motion observed at any stage in the periodic behavior.

We also need to consider two cases when the camera field of view is considerably smaller than the merging gap. An observing station near the eastern (i.e., duskward) end of the merging gap would see a transient 630 -nm event propagate from the west into its field of view as $\left|B_{y}\right|$ increased. This is consistent with the onset of events shown in Plate 1. However, as $\left|B_{y}\right|$ decreased again, this leading (eastward) edge of this event would retreat back to the west. This clearly does not occur in Plate 1 and this possibility can also be eliminated. An observing site near the western end of the merging gap would, as $\left|B_{y}\right|$ increased, observe an equatorward motion of the poleward edge of the 630-nm aurora, and this motion would propagate eastward. As $\left|B_{y}\right|$ decreased again, this would be followed by a poleward expansion of the $630-\mathrm{nm}$ aurora, which is propagating westward. This westward motion is inconsistent with the observations in Plate 1. However, it may be possible to postulate that the change in $B_{y}$ reaches the westward end of the reconnection $\mathrm{X}$ line first, and that its effect subsequently spreads eastward down the merging gap. Another alternative is that the decreasing $\left|B_{y}\right|$ causes an eastward relaxation of the merging gap. Hence it may be possible that the poleward expansion of the $630-\mathrm{nm}$ aurora may also propagate eastward. Hence of the three possibilities, only the third could be fitted to the optical observations presented in Plate 1 (by also invoking one or both of the above additional effects to conceal the westward return motion of the poleward expansion).

We conclude that the optical events presented in Plate 1 could possibly be fitted to the concept that they are caused by magnetosheath $B_{y}$ changes, as postulated by Newell and Sibeck [1993]. This would require the events (in which the 630-nm aurora expands poleward to greater latitudes) to move eastward over an observing site which observes the 
westward half of the merging gap. It also requires the field lines within such events to be reconnected to magnetosheath field lines of smaller $\left|B_{y}\right|$ (as in Figure 1a). The pcriods between the events would be those reconnected to magnetosheath field lines of higher $\left|B_{y}\right|$, such that the flow streamlines and the resulting cusp plume were more closely aligned with the polar cap boundary (as in Figure 1b), and the precipitation observed in the western part of the merging gap would not extend so far poleward as in the low $\left|B_{y}\right|$ case (Figure 1a). Comparisons of Figure $1 \mathrm{a}$ and $1 \mathrm{~b}$, for the only allowable observing site in the western half of the merging gap, shows that the model of $\left|B_{y}\right|$ changes predicts that the plasma flow will be faster (higher $T_{i}$ ) when the latitudinal band of $630-\mathrm{nm}$ emission is narrow (large $\left.\left|B_{y}\right|\right)$ and will be slower when it is broad (small $\left.\left|B_{y}\right|\right)$. However, the observations by the EISCAT radar reveal that this is in antiphase to what happens on this day. The enhanced ion temperatures are observed when the band of $630-\mathrm{nm}$ emissions is broad. The concept of $B_{y}$ changes in the magnetosheath, put forward by Newell and Sibeck [1993], therefore fails to explain the events.

\section{Could the Events be Caused by Pulses in the Reconnection Rate With Steady Magnetosheath $\mathrm{B}_{\mathrm{y}}$ ?}

In this section, we compare the predictions shown in Figure 2 with the images presented in Plate 1 and the events identified in Figure 4. It should be noted that Figure 2 represents the sequence for one isolated event, whereas Plate 1 shows part of a continuous sequence of such events. We infer an observing site just eastward of the merging gap: in each panel in figure 2, the dotted lines give the magnetic meridian ( $\mathbf{M}$ in figure 3 ) and the east and west segments of the circle of zenith angle $60^{\circ}$ for such a site. These dotted lines will thus be of assistance when comparing a panel in figure 2 with one of the observed images in Plate 1. By 0930 UT the first event is apparent in the poleward edge of the $630-\mathrm{nm}$ aurora to the west of the site and hence this situation corresponds to Figure 2d. The aurora then evolves, reaching the form predicted in Figure 2e by about 0937 UT and in Figure $2 \mathrm{f}$ by about 0940 UT (with an added complication, in that a second event is already forming, as is discussed below).

As this first event propagates and fades, Plate 1 shows that the second event is commencing as the southern boundary of the 630-nm aurora erodes equatorward: onset of this equatorward motion propagates eastward, reaching the $\mathrm{Ny}$ Allesund meridian at 0936 UT. Hence, Figure $2 \mathrm{c}$ explains the form of the equatorward edge of the $630-\mathrm{nm}$ band at $0936 \mathrm{UT}$, which subsequently evolves as in Figures $2 \mathrm{~d}-2 \mathrm{f}$ and $2 \mathrm{a}$. Note that until 0941 UT, the images are complicated by the residual effects of the first event, namely the poleward extrusion moving eastward along the poleward edge of the $630-\mathrm{nm}$ band. However, after 0941 UT the first event has faded and the second event dominates the images, Figure 2e corresponding to the image for 0945 UT and Figure $2 \mathrm{f}$ to that for 0949 UT. The aurora returns to a pre-event form (figure $2 \mathrm{a}$ )

The flow streamlines in Figure 2 show that rapid eastward flow (due to the curvature force associated with the inferred strongly negative IMF $B_{y}$ ) extends to lower latitudes as the event moves eastward over the meridian studied to the east of the merging gap. As shown in Figure 7, this is as observed by EISCAT on this day. The $T_{i}$ data show that the peak longitudinal flow does not reach down to gate 15 , although it is engulfed by 630 -nm aurora as the equatorward expansion at each event onset moves eastward. Hence, although most of the 630-nm event is within the region of rapid longitudinal flow, there is a thin band, roughly $60 \mathrm{~km}$ wide, on the equatorward edge of the auroral event which is not flowing so rapidly: Figure 7 shows that the ion temperatures increase with latitude across this region (gates 14-16) as the optical event passes over. This is consistent with the model because $630-\mathrm{nm}$ emission will be caused by cleft/LLBL precipitation on the equatorward edge of the main event. This $630-\mathrm{nm}$ cleft aurora could be due to an open LLBL population on the most recently opened field lines as electrons can arrive (and cause the emission) before sufficient Alfvén wave bounces have occurred to transfer the full longitudinal motion to the ionosphere (giving the high $T_{i}$ ). The rise in $T_{i}$ with latitude over this region is then consistent with the rise in longitudinal flow with elapsed time since reconnection (as each newly opened field line accelerates). However, Figure 2 shows how this region could also bc caused by an LLBL population on closed field lines. Figures $2 \mathrm{c}$ and $2 \mathrm{~d}$ show a closed LLBL aurora moving south ahead of the eastward advancing extrusion of the open/closed field line boundary.

The key prediction is that, unlike for the magnetosheath $B_{y}$ changes, the flow burst (peak $T_{i}$ ) should be observed at the same time as the $630-\mathrm{nm}$ event (defined from the broadening of the $630-\mathrm{nm}$ auroral band) passes over the radar sites, as has been demonstrated here for the data on January 20, 1990.

We conclude that the events shown are consistent with pulsed magnetopause reconnection and a steady magnetosheath $B_{y}$.

\section{Conclusions}

We have demonstrated that the events seen by EISCAT and the 630-nm optical camera on January 20, 1990, were consistent with pulsed magnetopause reconnection, but were inconsistent with the effects of magnetosheath $B_{y}$ changes with steady magnetopause reconnection.

The important features of the events discussed here (namely the coincidence of the cnhanced flow with the 630$\mathrm{nm}$ transient events in time and space and the fact that events move repetitively in one direction and do not oscillate in longitudinal position), are also found in the other longitudinal flow burst events we have observed in association with dayside 630-nm transients, as reported in the literature [Sandholt et al., 1990; Lockwood et al., 1990; Lockwood et al., 1993c; Moen et al., 1995]. We conclude that the events reported here, and the previously reported longitudinal flow bursts associated with transient dayside auroral events, are consistent with pulsed reconnection with a magnetosheath field and are inconsistent with the concept of Newell and Sibeck [1993] that they are caused by pulsed magnetosheath $\mathrm{B}_{\mathrm{y}}$ with a steady reconnection rate.

\section{How Pulsed is the Reconnection During the Events?}

Figure 7 has an interesting implication for the behavior of the reconnection rate, if we adopt the pulsed reconnection interpretation favoured by the discussion in the previous section. If the reconnection were to be pulsed but continuous (as used to derive Figure 2), then at all times a region of peak longitudinal flow would exist somewhere, that is if the 
magnetosheath conditions remained constant, such that the pattern of motion of each newly opened flux tube remained the same. Between the pulses, the width of that region would be smaller, but continuous reconnection would ensure that there was a continuous supply of newly opened field lines and hence there would always be some field lines moving at peak longitudinal velocity. In turn this means that, in the examples presented here, there would always be ion temperatures of order $5500-7000 \mathrm{~K}$ present. The gate(s) in which these high ion temperatures are found would change with time as the open/closed boundary moved in latitude.

On the other hand, if the reconnection were fully pulsed (i.e., the reconnection rate falls to zero between the pulses), the flow would decrease at all latitudes at the end of each event. This would be caused by the decay of the magnetic curvature force on the last of the newly opened field lines as they straighten. Hence in this case, the peak flows (and peak ion temperatures) would not be found at any latitude between events. However, one must be careful in stating that the failure to observe continued high ion temperatures would mean that reconnection between the pulses is entirely absent. This is because one must place an observational caveat on this discussion. The range resolution of the radar measurements is $37.5 \mathrm{~km}$. Hence if the region of maximum longitudinal flow is present, but very narrow (less than about $15 \mathrm{~km}$ ), the radar experiment would not resolve such a narrow region of high ion temperature, but would spatially average regions of high and low temperature in a complex manner depending on the spectral fit to the integrated radar echoes. In addition, the ion temperature will decay slowly as the field lines straighten. Hence if the pulses are sufficiently close together, the decay of the ion temperatures may go undetected.

Figure 7 demonstrates that a narrow region of high ion temperatures exists between the events on January 20, 1990, and that this region broadens as the 630 -nm transient events pass over the radar. We can conclude that for the pulsed reconnection model, the reconnection must have been continuous for this example; i.e., there was ongoing reconnection at a lower rate between the pulses of enhanced rate. Hence, for example, a low-altitude spacecraft would observe steepenings of the cusp ion dispersion signature on the boundaries between successive 630-nm events [Lockwood and Smith, 1994]. These steps would not, however, be as steep as the instantaneous steps which would be produced by fully pulsed reconnection, with no reconnection taking place between the pulses [e.g. Lockwood et al., 1993a].

Figure 7 can be used to gain some insight into how pulsed the reconnection would have to be for this model of the events. Between the events, the band of high ion temperature $\left(T_{i}>5500 \mathrm{~K}\right)$ is $w_{1}=30 \mathrm{~km}$ wide (one range gate), whereas within the first event it is $w_{2}>150 \mathrm{~km}$ wide (5 range gates), this being a lower limit because the events extend beyond the poleward limit of the radar field of view. The curvature of the newly opened field lines will decrease as they straighten, such that they will drive ion temperatures in the ionosphere which exceed $5500 \mathrm{~K}$ for a certain interval after the longitudinal flow commences: let the length of this interval be $\Delta t$. From the time constant of the decay of $T_{i}$ in some range gates at the end of the event we estimate $\Delta t$ is at least $3 \mathrm{~min}$ for the $5500 \mathrm{~K}$ threshold. If we consider a reference frame in which the merging gap is a rest, the plasma will move poleward at a speed $V^{\prime}$, which is directly proportional to the magnetopause reconnection rate $\left(V^{\prime}\right.$ is the sum of the equatorward boundary speed and the poleward convection speed normal to the boundary in the Earth's frame [Lockwood et al., 1993b]). The latitudinal width of the region of ion temperature exceeding the $5500 \mathrm{~K}$ threshold chosen here will then be

$$
w=\int_{0}^{\Delta t} V d t
$$

For a steady background reconnection rate of $V^{\prime}=a$, the width of the region will therefore be $w_{1}=a \Delta t$. If there is a square-wave pulse of enhanced reconnection rate (in which $V^{\prime}=b$ ) which lasts for a time $\delta$, the cusp width increases to a maximum of $w_{2}$, where

$$
w_{2}=a(\Delta t-\delta)+b \delta .
$$

Hence the ratio of the reconnection rates in and between the pulses is

$$
b / a=1+\left(w_{2} / w_{1}-1\right)(\Delta t / \delta)
$$

From Figure 7 we know $\left(w_{2} / w_{1}\right)>5$ for the first event. The equatorward expansion of ion temperatures $>5500 \mathrm{~K}$ is almost instantaneous as the rise in $T_{i}$ is almost simultaneous at all gates, from which we infer $\delta$ is less than about $1 \mathrm{~min}$. This is broadly consistent with the duration of magnetopause FTE signaturcs [Lockwood and Davis, 1994] and the duration derived from stepped cusp ion dispersion signatures [Lockwood and Smith, 1992]. Using the maximum estimate for $\delta$ of $1 \mathrm{~min}$, with the minimum estimates for $w_{2} / w_{1}$ and $\Delta t$ of respectively 5 and $3 \mathrm{~min}$, gives a minimum estimate for the ratio bla. From (4) we then deduce that the ratio b/a is at least 13 and could be considerably greater. Hence the pulses giving the events must be at least a tenfold increase in the magnetopause reconnection rate.

Acknowledgments. The authors thank the director and staff of the EISC.AT Association. EISCAT is made up of the research councils of 6 European nations: France, Germany, Sweden, Norway, Finland and the United Kingdom.

The editor thanks C.A. Gurgiolo and another referee for their assistance in evaluating this paper.

\section{References}

Atkinson, G., Magnetospheric flows and substorms, in Magnetosphere-Ionosphere Interactions, edited by $\mathrm{K}$. Folkestadt, p. 203, Universitetsforlaget, Oslo, Norway, 1972.

Brace, L.H., R.F. Theis, and W.R. Hoegy, A global view of the F-region electron density and temperature at solar maximum, Geophys. Res. Lett., 9, 989-992, 1982.

Burch, J.L., Rate of erosion of dayside magnetic flux based on a quantitative study of polar cusp latitude on the interplanetary magnetic field, Radio Sci., 8, 955-961, 1973.

Cowley, S.W.H., Magnetospheric symmetries associated with the $Y$-component of the IMF. Planet Space Sci., 29, 79, 1981.

Cowley, S. W. H., The causes of convection in the Earth's magnetosphere: A review of developments during IMS, Rev. Geophys., 20, 531-565, 1982.

Cowley, S.W.H. J.P. Morelli, and M. Lockwood, Dependence of convective flows and particle precipitation in the high-latitude dayside ionosphere on the $X$ and $Y$ components of the interplanetary magnetic field, J. Geophys. Res., 96, 5557-5564, 1991a.

Cowley, S.W.H., M.P. Freeman, M. Lockwood, and M.F. Smith, 
The ionospheric signature of flux transfer events, in CLUSTER - Dayside Polar Cusp", Eur. Space Agency Publ. SP-330, 105-112, $1991 \mathrm{~b}$.

de la Beaujardiere O., P. Newell, and R. Rich, Relationship between Birkeland current regions, particle participation, and electric fields, J. Geophys. Res., 98, 7711-7720, 1993.

Dungey, J.W., Waves and Particles in the magnetosphere, in The Physics of the Magnetosphere, edited by R. L. Carovillano, J. F. McClay and H. R. Radoski, p. 246, D. Riedel, Norwell, Mass., 1968.

Eather, R.H., Polar cusp dynamics, J. Geophys. Res., 90, 15691576, 1985.

Eather, R.H. and S.B. Mende, Airborne observations of auroral precipitation patterns, J. Geophys. Res., 76, 1746, 1971.

Elphic, R. C., M. Lockwood, S. W. H. Cowley, and P. E. Sandholt, Signatures of flux transfer events at the dayside magnetopause and in the ionosphere: Combined ISEE, EISCAT and optical observations, Geophys. Res. Lett.; 17, 2241-2244, 1990.

Elphinstone, R.D., J.S. Murphree, D.J. Hearn, L.L. Cogger., P.T. Newell, and H. Vo, Viking observations of the UV dayside aurora and their relation to DMSP particle boundary definitions, Ann. Geophys., 10, 815-826, 1992.

Frank, L.A., Plasmas in the Earth's polar magnetosphere, $J$. Geophys. Res., 76, 5202, 1971.

Fuselier, S.A., D.M. Klumpar, and E.G. Shelley, Ion reflection and transmission during reconnection at the Earth's subsolar magnetopause, Geophys. Res. Lett., 18, 139-142, 1991.

Gosling, J.T., M.F. Thomsen, S.J. Bame, R.C. Elphic, and C.T. Russell, Plasma flow reversals at the dayside magnetopause and the origin of asymmetric polar cap convection, J. Geophys. Res., 95, 8073-8084. 1990a.

Gosling, J.T., M.F. Thomsen, S.J. Bame, T.G. Onsanger, and C.T. Russell, The electron edge of the low-latitude boundary layer during accelerated flow events, Geophys. Res. Lett., 17, 1833-1836, 1990b.

Gosling, J.T., M.F. Thomsen, S.J. Bame, R.C. Elphic, and C.T. Russell, Cold ion beams in the low-latitude boundary layer during accelerated flow events, Geophys. Res. Lett., 17, 22452248, 1990c.

Greenwald, R.A., K.. Baker, J.M. Ruohoniemi, J.R. Dudeney, M. Pinnock, N. Mattin, and J.M. Leonard, Simultaneous conjugate observations of dynamic variations in high-latitude dayside convection due to changes in IMF $B_{y}, J$. Geophys. Res., 95, 8057, 1990.

Heikkila, W.J., The morphology of auroral particle precipitation, Space Res., 12, 1343, 1972.

Heikkila, W.J., and J.D. Winningham, Penetration of magneto sheath plasma to low altitudes through the dayside magnetospheric cusps, J. Geophys. Res., 76, 883, 1971.

Horwitz, J.L., and S.-I. Akasofu, The response of dayside aurora to sharp northward and southward transitions of the interplanetary magnetic field and to magnetospheric substorms, $J$. Geophys. Res., 82, 2723-2734, 1977.

Jørgenson, T.S., E. Friis-Christensen, and J. Wilhjelm, Interplanetary magnetic direction and high latitude ionospheric currents, J. Geophys. Res., 77, 1976, 1972.

Kozyra, J.V., C.E. Valladares, H.C. Carlson, M.J. Buonsanto, and D.W, Slater, A theoretical study of the seasonal and solar cycle variations of stable auroral red arcs, J. Geophys. Res., 95, 12219-12234, 1990.

Lockwood, M. and S.W.H. Cowley, Ionospheric convection and the substorm cycle, in Proceedings of the First International Conference on Substorms (ICS-1), Kiruna 23-27 March, 1992, Eur. Space Agency Spec. Publ. SP-335, 101, 1992.

Lockwood, M., and S.W.H. Cowley, Comment on "Ionospheric signatures of dayside magnetopause transients: A case study using satellite and ground measurements" by Denig et al., $J$. Geophys. Res., 99, 4253, 1994.
Lockwood, M., and C.J. Davis, The occurrence probability, width and terracing of cusp precipitation in the topside ionosphere for fully-pulsed reconnection at the dayside magnetopause, J. Geophys. Res., this issue.

Lockwood, M., and M.F. Smith, The variation of reconnection rate at the dayside magnetopause and cusp ion precipitation, J. Geophys. Res., 97, 14841-14847, 1992.

Lockwood, M., and M.F. Smith, Low- and mid-altitude cusp particle signatures for general magnetopause reconnection rate variations: I - Theory, J. Geophys. Res., 99, 8531-8555, 1994.

Lockwood, M., and M.N. Wild, On the quasi-periodic nature of magnetopause flux transfer events, J. Geophys. Res., 98, 59355940, 1993.

Lockwood, M., P.E. Sandholt, and S.W.H. Cowley, Dayside auroral activity and magnetic flux transfer from the solar wind, Geophys. Res. Lett., 16, 33-36, 1989a.

Lockwood, M., P.E. Sandholt, S.W.H. Cowley, and T. Oguti, Interplanetary magnetic field control of dayside auroral activity and the transfer of momentum across the dayside magnetopause, Planet. Space Sci., 37, 1347, $1989 \mathrm{~b}$.

Lockwood, M., S. W. H. Cowley, P. E. Sandholt, and R. P. Lepping, The ionospheric signatures of flux transfer events and solar wind dynamic pressure changes, J. Geophys. Res.; 95, 17113-17135, 1990.

Lockwood, M, W.F. Denig, A.D. Farmer, V.N. Davda, S.W.H. Cowley, and H. Lühr, Ionospheric signatures of pulsed magnetic reconnection at the Earth's magnetopause, Nature, 361, (6411), 424-428, 1993a.

L.ockwood, M., J. Moen, S.W.H. Cowley, A.D. Farmer, U.P. Løvhaug, H. Lühr, and V.N. Davda, Variability of dayside convection and motions of the cusp/cleft aurora, Geophys. Res. Lett., 20, 1011-1014, 1993 b.

Lockwood, M., H.C. Carlson, and P.E. Sandholt, The implica tions of the altitude of transient $630-\mathrm{nm}$ dayside auroral emissions, J. Geophys. Res., 98, 15571-15587, 1993 c.

Lockwood, M., I.W. McCrea, G.H. Millward, R.J. Moffett, and H. Rishbeth, EISCAT observations of ion composition and temperature anisotropy in the high-latitude F-region, J. Atmos. Terr. Phys., 55, 895-906 1993d.

Lockwood, M., S.W.H. Cowley, and M.F. Smith, Comment on " $B_{y}$ fluctuations in the magnetosheath and azimuthal flow velocity transients in the dayside ionosphere" by Newell and Sibeck, Geophys. Res. Lett., 21, 1819-1820, 1994.

Mantas, G.P., and J.C.G. Walker, The penetration of soft electrons into the ionosphere, Planet. Space Sci., 24, 409-423, 1976.

Maynard, N.C., T.L. Aggson, E.M. Basinska, W.J. Burke, P. Craven, W.K. Peterson, M. Sugiura, and D. Weimer, Magnetospheric boundary dynamics: DE 1 and DE 2 observations near the magnetopause and the cusp, J. Geophys. Res., 96, 3505-3522, 1991.

McCrea, I.W., M. Lester, T.R. Robinson, J.-P. St.-Maurice, N.M. Wade, and T.B. Jones, Derivation of the ion temperature partition coefficient $\beta$ from the study of ion frictional heating events, J. Geophys. Res., 98, 15701-15715, 1993.

Meng, C.-I., Case studies of the storm time variation of the polar cusp, J. Geophys. Res., 88, 137, 1983.

Moen, J., M. Lockwood, P.E. Sandholt, U.P. Løvhaug, W,F. Denig, A.P van Eyken, and A. Egeland, Variability of dayside high-latitude convection associated with a sequence of auroral transients, J. Atmos. Terr. Phys., in press, 1995.

Newell, P.T., and D.G. Sibeck, $B_{y}$ fluctuations in the magneto sheath and azimuthal flow velocity transients in the dayside ionosphere, Geophys. Res. Lett., 20, 1719-1723, 1993.

Newell P.T., and D.G. Sibeck, Reply, Geophys. Res, Lett., 21, 1821-1822, 1994.

Newell, P.T., W.J. Burke, C.-I. Meng, E.R. Sanchez, and M.E. Greenspan, Identification an observation of the plasma mantle at low altitude, J. Geophys. Res., 96, 3545, 1991. 
Paschmann, G., The Earth's magnetopause, in Achievements of the International Magnetospheric Study, IMS, Eur. Space Agency Spec. Publ. SP-217, 53-64, 1984.

Paschmann, G., B.U.Ö. Sonnerup, I. Papamastorakis, N. Sckopke, G. Haerendel, S.J. Bame, J.R. Asbridge, J.T. Gosling, C.T. Russell, and R.C. Elphic, Plasma acceleration at the Earth's magnetopause: Evidence for reconnection, Nature, 282, 243-246, 1979.

Paschmann, G., I. Papamastorakis, W. Baumjohann, N. Sckopke, C.W. Carlson, B.U.Ö. Sonnerup, and H, Lühr, The magnetopause for large magnetic shear: AMPTE/IRM observations, $J$. Geophys. Res., 91, 11099-11115, 1986.

Paschmann, G., B.U.Ö. Sonnerup, I. Papamastorakis, W. Baumjohann, N. Sckopke, and H, Lühr, The magnetopause and boundary layer for small magnetic shear: Convection electric fields and reconnection, Geophys. Res. Lett., 17, 1829$1832,1990$.

Rees, M.H., and R.G. Roble, Excitation of the $O\left({ }^{1} D\right)$ atoms in aurora and emission of the [OI] $6300 \AA$ line, Can. J. Phys., 64, 1608-1613, 1986.

Reiff, P. H., T. W. Hill, and J. L. Burch, Solar wind plasma injection at the dayside magnetospheric cusp, J. Geophys. Res., 82, 479-491, 1977.

Reiff, P. H., J.L. Burch, and R. W. Spiro, Cusp proton signatures and the interplanetary magnetic field, J. Geophys. Res., 85, 5997, 1980.

Sanchez, E.R., and G.L. Siscoe, IMP 8 magnetotail boundary crossings: a test of the MHD models for an open magnetosphere, J. Geophys. Res., 95, 20771-20779, 1990.

Sanchez, E.R., G.L. Siscoe, J.T. Gosling, E.W. Hones Jr., and R.P. Lepping, Observations of rotational discontinuity-slow mode expansion fan structure of the magnetotail boundary, $J$. Geophys. Res., 95, 61-73, 1990.

Sandford, B.P., Aurora and airglow intensity variations with time and magnetic activity at southern high latitudes, J. Atmos. Terr. Phys., 26, 749, 1964.

Sandholt, P.E., IMF control of the polar cusp and cleft auroras, Adv. in Space Res., 8(9), 21-34, 1988.

Sandholt, P.E., A. Egeland, C.S. Deehr, G.G. Sivjee, and G.J. Romick, Effects of interplanetary magnetic field and magnetic substorm variations on the dayside aurora, Planet. Space Sci., $31,1345,1983$.

Sandholt, P.E., A. Egeland, J.A. Holtet, B. Lybekk, K.Svenes, and S. Asheim, Large- and small-scale dynamics of the polar cusp, J. Geophys. Res., 90, 4407-4414, 1985.

Sandholt, P.E., B. Lybekk, A. Egeland, B. Jacobson, P.F. Bythrow, and D.A. Hardy, Electrodynamics of the polar cusp ionosphere - A case study, J Geophys. Res., 94, 6713-6722, 1989a.

Sandholt, P.E., B. Lybekk, A. Egeland, R. Nakamura, and T. Oguti, Midday auroral breakup, J. Geomagn. Geoelectr., 41, 371-387, 1989b.

Sandholt, P. E., M. Lockwood, T. Oguti, S. W. H. Cowley, K. S. C. Freeman, B. Lybekk, A. Egeland, and D.M. Willis, Midday auroral breakup events and related energy and momentum transfer from the magnetosheath, J. Geophys. Res., 95, 1039-1060, 1990.

Sandholt, P.E., J. Mocn, and D. Opsvik, Periodic auroral events at the midday polar cap boundary: Implications for solar wind-magnetosphere coupling, Geophys. Res. Lett., 19, 12231226, 1992.

Sandholt, P.E., J. Moen, A. Rudland, D. Opsvik, W.F. Denig, and T. Hansen, Auroral event sequences at the dayside polar cap boundary for positive and negative interplanetary magnetic field $B_{y}, J$. Geophys. Res., 98, 7737-7755, 1993.

Smith, M.F., and D.J. Rodgers, Ion distributions at the dayside magnetopause, I. Geophys. Res., 95, 11617-11624, 1991.

Smith, M.F., M. Lockwood, and S.W.H. Cowley, The statistical cusp: A simple flux transfer event model, Planet. Space Sci. 40, 1251-1268, 1992.

Sonnerup, B.U.O., G. Paschmann, I. Papamastorakis, N. Sckopke, G. Haerendel, S.J. Bame, J.R. Ashbridge, J.T. Gosling, and C.T. Russell, Evidence for magnetic field reconnection at the Earth's magnetopause, J. Geophys. Res., 86, 10049-10067, 1981.

Starkov, G.V., and Y.I. Feldstein, Scheme of an elementary disturbance on auroras on the dayside of the Earth, Geomag. Aeron. (Engl. Trans.), 7, 294, 1967.

Taguchi, S., M. Sugiura, J.D. Winningham, and J.A. Slavin, Characterization of the IMF $B_{y}$ dependent field-aligned currents in the cleft region based on DE 2 observations, $J$. Geophys. Res., 98, 1393-1407, 1993.

Tereshchenko, V.D., E.D. Tereshchenko, and H. Kohl, The incoherent scattering of radio waves in a non-Maxwellian plasma: The effect of Coulomb collisions, J. Geophys. Res., 96, 17591-17598, 1991.

Titheridge, J.E., Ionospheric heating beneath the magnetospheric cleft, J. Geophys. Res., 81, 3221-3226, 1976.

Vorobjev, V.G., G. Gustafsson, G.V. Starkov, Y.I. Feldstcin, and N.F. Shevnina, Dynamics of day and night aurora during substorms, Planet. Space Sci., 23, 269, 1975.

Watermann, J., O. de la Beaujardiere, and P.T. Newell, Incoherent scatter radar observations of ionospheric signatures of cusp-like electron precipitation, J. Geomagn. Geoelectr., 44, 1195-1206, 1992.

Whalen, J.A., J. Buchau, and R.A. Wagner, Airborne ionospheric and optical observations of noon-time aurora, J. Atmos. Terr. Phys., 33, 661, 1971.

Wickwar, V.B. and W. Kofman, Dayside auroras at very high latitudes: the importance of thermal excitation, Geophys. Res. Lett., 11, 923-926, 1984.

Wickwar, V.B., L.L Cogger, and H.C. Carlson, The $6300 \AA$ $\mathrm{O}\left({ }^{1} \mathrm{D}\right)$ airglow and dissociative recombination, Planet. Space Sci., 22, 709-724, 1974.

Willis, D.M., M. Lockwood, S.W.H. Cowley, H. Rishbeth, A.P. van Eyken, B.J.I. Bromage, P.R. Smith, and S.R. Crothers, A survey of simultaneous observations of the high latitude ionosphere and interplanetary magnetic field with EISCAT and AMPTE-UKS, J. Atmos. Terr. Phys., 48, 987-1008, 1986.

S. W. H. Cowley, Blackett Laboratory, Imperial College, London SW7 2BZ, Unitcd Kingdom.

M. Lockwood, Rutherford Appleton Laboratory, Chilton, Didcot, OX11 0QX, United Kingdom. (e-mail: mike@eiscat.ag.rl. ac.uk)

U. P. Løvhaug, EISCAT Scientific Association, Ramfjordmoen, N-9027, Ramfjordbotn, Norway.

P. E. Sandholt, Department of Physics, University of Oslo, Box 1048, Blindern 0316, Oslo 3, Norway.

(Received January 31, 1994; revised August 22, 1994; accepted August 25, 1994.) 